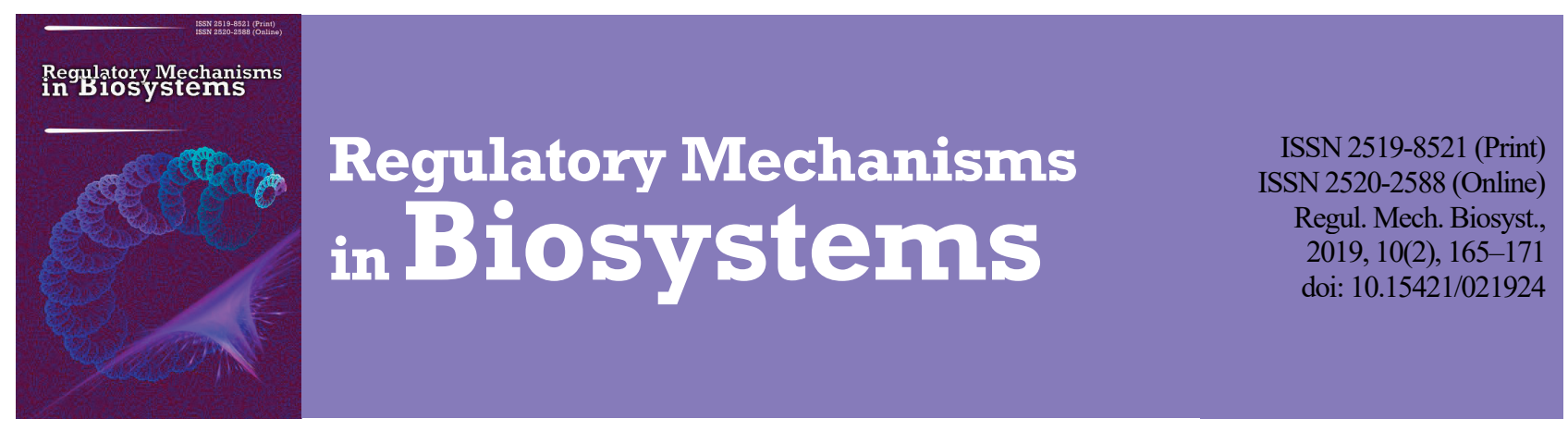

\title{
Morphobiological analysis of Trichuris vulpis (Nematoda, Trichuridae), obtained from domestic dogs
}

\author{
V. A. Yevstafieva*, S. O. Kravchenko*, B. V. Gutyj**, V. V. Melnychuk*, P. N. Kovalenko*, L. B. Volovyk* \\ * Poltava State Agrarian Academy, Poltava, Ukraine \\ **Lviv National University of Veterinary Medicine and Biotechnologies named after S. Z. Gzhytskyj, Lviv, Ukraine
}

Article info

Received 16.04.2019

Received in revised form 10.05 .2019

Accepted 12.05.2019

Poltava State Agrarian

Academy, Skovorody st., 1/3,

Poltava, 36003, Ukraine.

Tel.:+38-050-183-78-78.

E-mail:evstva@ukr.net

Lviv National University

of Veterinary Medicine

and Biotechnologies

named after S. Z. Gzhytskyj,

Pekarska st., 50,

Lviv, 79000, Ukraine.

Tel.: +38-068-136-20-54.

E-mail:bvh@ukr.net

\section{Introduction}

The nematodes of the genus Trichuris (Nematoda, Trichuridae) are a group of the most common parasitic pathogens in various climatic and geographic regions (Soulsby, 1982; Anderson, 2000; Bethony et al., 2006; Ghai et al., 2014). The adult and larval parasites live in organisms of mammals such as ruminants, marsupials, carnivores, rodents and primates. The embryonic life stages of parasites develop in the environment (Hasegawa \& Dewi, 2017; Xie et al., 2018; Yevstafieva et al., 2018; Eo et al., 2019). Currently, there are almost 80 species in the genus Trichuris, and most of them are parasites of specific host taxa (Callejón et al., 2016). Researchers in many countries are interested in this parasitic group because of the danger it poses to humans. According to certain statistics, in total $465,000,000$ humans are infected with trichuriasis (Stephenson et al., 2000; Pullan et al., 2014; Betson et al., 2015; Adriko et al., 2018).

Many studies confirm that Trichuris vulpis (Frölich, 1789) is widely distributed in domestic and wild carnivores (Di Cesare et al., 2012; Redman et al., 2016; Varodi et al., 2017; Karamon et al., 2018). It is also established that this species can parasitize in humans. Cross-infections of humans are possible from their pet dogs and cats, which are the definitive hosts of T. vulpis (Sakano et al., 1980; Singh et al., 1993; Areekul et al., 2010; Mohd-Shaharuddin et al., 2019). This species is common in domestic dog (Canis lupus familiaris Linnaeus, 1758) populations. For example, $43 \%$ of examined dogs in Brazil were infected with $T$. vulpis, the abundance index was 10.03 , with intensity of infection ranging 1 to Italy, prevalence of this nematode species in dogs ranged 5.8\% to 11.1\% (Zanzani et al., 2014; Scaramozzino et al., 2018). In South Africa, $7.9 \%$ of dogs were diagnosed with trichuriasis, compared to the maximum 3\% and 4\% in Chile and Germany, respectively (Barutzki \& Schaper, 2003; Mukaratirwa \& Singh, 2010; Opazo et al., 2019).

Nematode taxa are identified by several morphological and metric characters. The nematodes of the genus Trichuris are similar by their body structure: the anterior part is elongated to filiform, and the posterior part is thicker. Hence in species identification, the following characters are considered: the length of body in males and females; the spicule sheath surface, shape and ornamentation; the spicule length, the shape of its proximal and distal ends; the morphology of the vulva, the structural specifics of the cuticle (Spakulová, 1994; Robles et al., 2006; Ketzis, 2015). Coprological differentiation of the eggs of T. trichiura and T. vulpis has epidemiological significance; hence, a more detailed morphometric study of embryonic stages of $T$. vulpis is of interest to improve diagnosis of the disease caused by this Trichuris species (Kagei et al., 1986; Yoshikawa et al., 1989; Dunn et al., 2002).

The adaptations supporting the wide distribution of parasitic nematodes in the host populations are shaped to a large extent by several factors including the biological features of the parasite species such as the nature of their interactions with the environment at all stages of ontogenesis (Boyko \& Brygadyrenko, 2016, 2017). One of the important biological adaptations which allows Trichuris nematodes to persist and disseminate is the exogenous egg developpment, i.e. the maturation of 
egg to the infectious stage in the environment (Fahmy et al., 1954; Lee, 2002; Stroehlein et al., 2017). There are reports of embryogenesis of Trichuris nematodes, according to which the features distinguishing egg development stages, egg viability and metric parameters are speciesspecific and can be used in species identification (Fataliev, 3013; Yevstafieva et al., 2015; Melnychuk \& Berezovsky, 2018). Thus, a comprehensive study of morphobiological specifics of T.vulpis parasitizing domestic dogs is not only of interest in itself but is of significant importance for the diagnostics of that zoonosis.

The objective of the present research was studying the species morphometric identification parameters of mature $T$. vulpis nematodes (Nematoda, Trichuridae) parasitizing in dogs, and to establish the specifics of the parasite's embryogenesis in laboratory culture.

\section{Materials and methods}

The parasitological analysis of $T$. vulpis nematodes was conducted in 2017-2018. Nematodes were collected during helminthological investigation of the large intestine of 63 dead domestic dogs (Skriabyn, 1928). The Trichuris species was identified using identification keys (Skriabyn et al., 1957). In morphological analysis, 376 adult specimens of $T$. vulpis (172 males and 204 females) were used.

To study the biological specifics of $T$. vulpis nematodes in laboratory culture, eggs were collected from gonads of female nematodes. Each separate culture was placed in a Petri dish and cultured in a thermostat at $27^{\circ} \mathrm{C}$ to the point of mobile larva formation. The cultures were examined every three days under a light microscope. The stage of development was identified by morphology of the embryo, also eggs that had stopped developing or were destroyed were counted. Each experiment was performed in triplicate.

Morphometric parameters of adult and embryonic life stages of T. vulpis were studied using the software ImageJ for Windows ${ }^{\mathbb{B}}$ (version 2.00) in interactive mode using $10^{\times}, 40^{\times}, 100^{\times}$objective and $10^{\times}$ photo eyepiece. To calibrate the image analyzer, the ruled scale of the ocular micrometer was aligned with the scale of stage micrometer included in MikroMed microscope kit. Microphotographs were taken using a digital camera of MikroMed 5 Mpix (China) microscope.

Statistical processing of the experimental results was carried out using standard deviation (SD) and average values (x) were calculated. Significance of difference between average values in the studied nematode groups was established using one-way analysis of variance and Ftest for $95 \%$ confidence level.

\section{Results}

It was established that the T. vulpis nematodes were morphologically similar to other Trichuris nematodes in the external body structure. Thus, their anterior body part was elongated, filiform, the posterior body part was strongly thickened and short. Notably, in males the posterior part was sharply bent and sometimes coiled in a spiral, in females the posterior part was slightly curved like a sickle (Fig. 1).

The mouth was terminal, with slightly protruding lips (Fig. 2a), opening into a very thin and long esophagus seemingly immersed in a well-defined stichocyte layer (Fig. $2 b$ ). The transition of esophagus to gut was located at the beginning of the thickened posterior body part. The cuticle was with slight transverse striation. Vesicular cuticular processes were characteristic for the surface of the anterior body part of these nematodes (Fig. 2c), both in males and in females.

The morphological study of $T$. vulpis males resulted in the following observations. The tail end was strongly curved and shaped like a bluntly rounded cone. The spicule was singular, long and filiform. Its distal end was thinner and rounded; its proximal end was widened into a funnel. The spicule sheath tightly covered the spicule (Fig. 3). Males of this species were distinguished by spikes at the proximal part of the spicule sheath (Fig. 4a) in contrast to the distal part of spicule sheath, without spikes (Fig. 4b). That character was easily seen on a maximally protruding spicule sheath. In $T$. vulpis females, the vulval opening was located posteriorly to the end of the esophagus and the proximal end of gut.

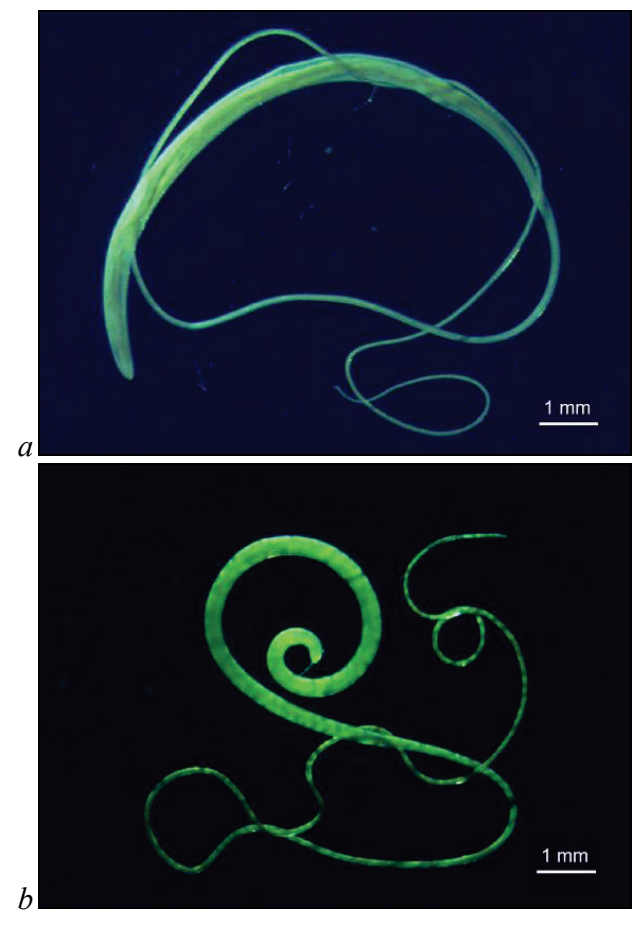

Fig. 1. The general view of adult Trichuris vulpis nematodes: $a-q ; b-\hat{\sigma}$
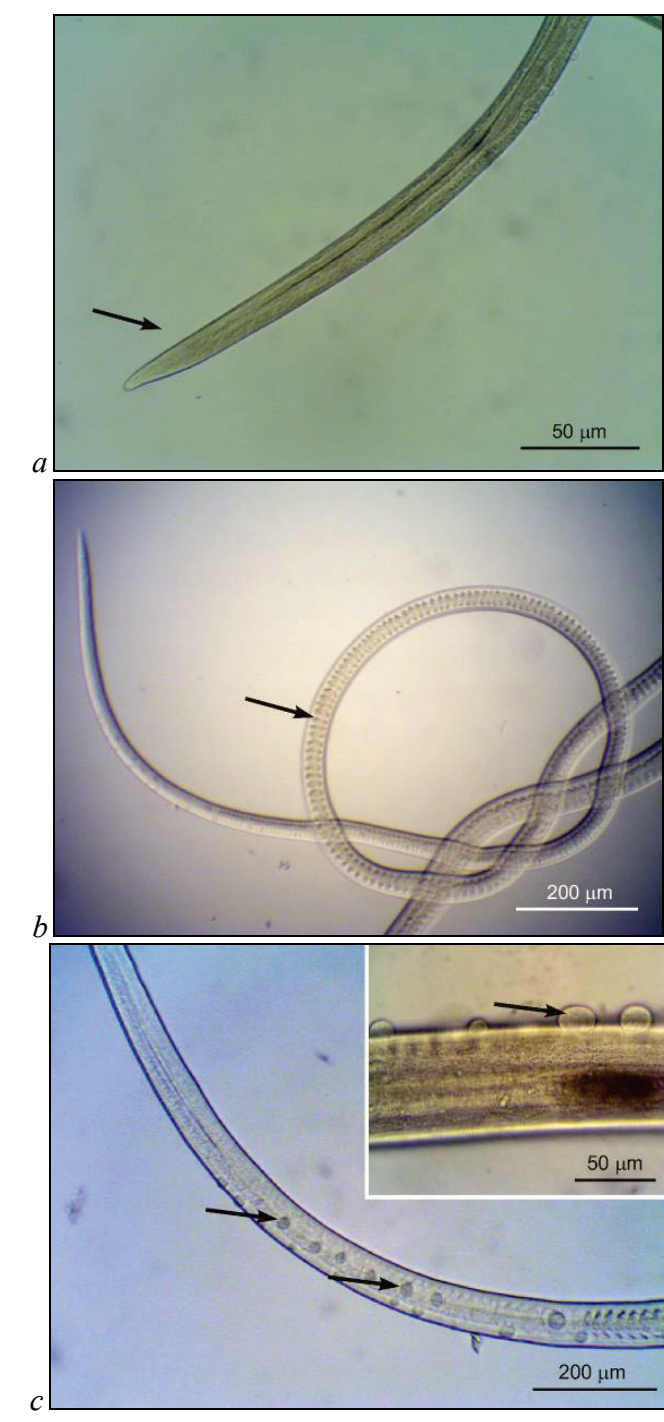

Fig. 2. Trichuris vulpis: $a$-anterior end, $b$ - esophagus with stichocytes, $c-$ cuticular processes 


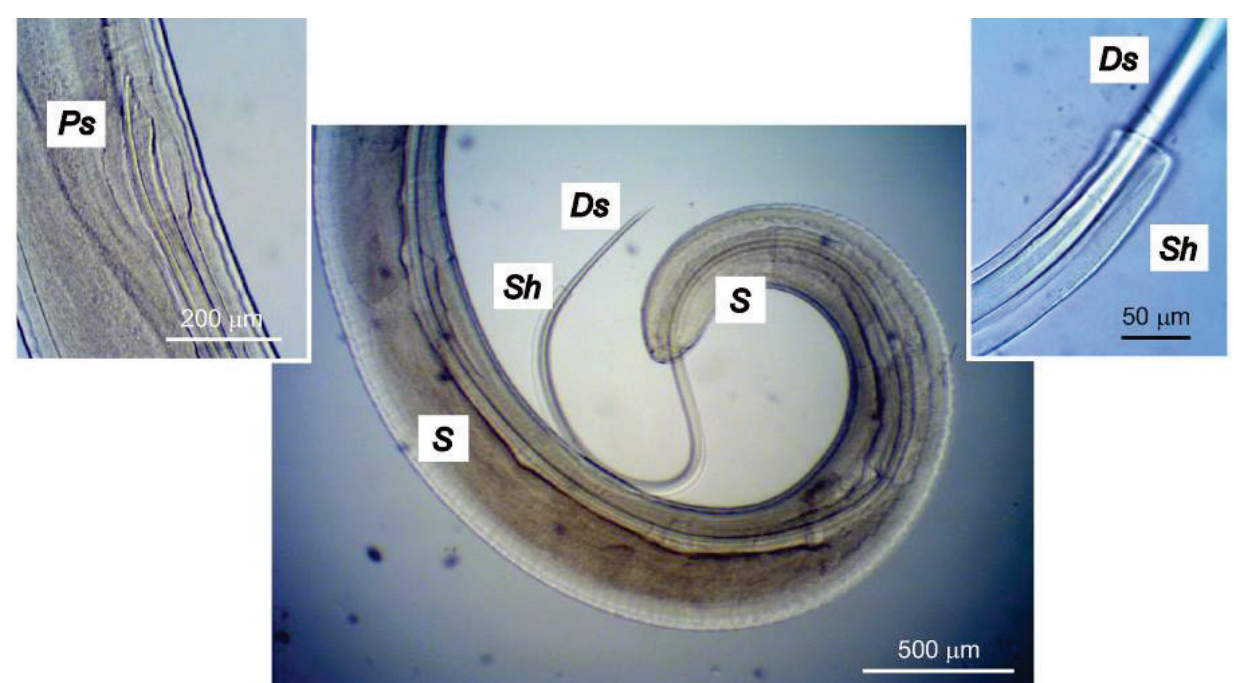

Fig. 3. $\widehat{\bigcirc}$ Trichuris vulpis: $S h$ - spicule sheath, $S$-spicule, $P S$ - proximal end of spicule, $D s-$ distal end of spicule
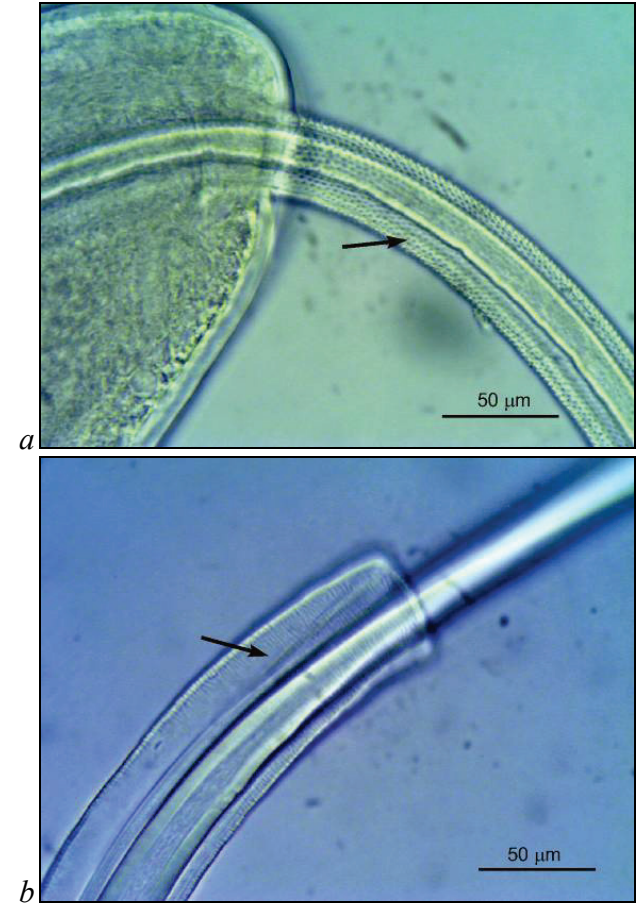

Fig. 4. Specifics of spicule sheath structure in $\widehat{\partial}$ Trichuris vulpis: $a$-spikes in proximal part, $b$ - smooth surface of the distal part

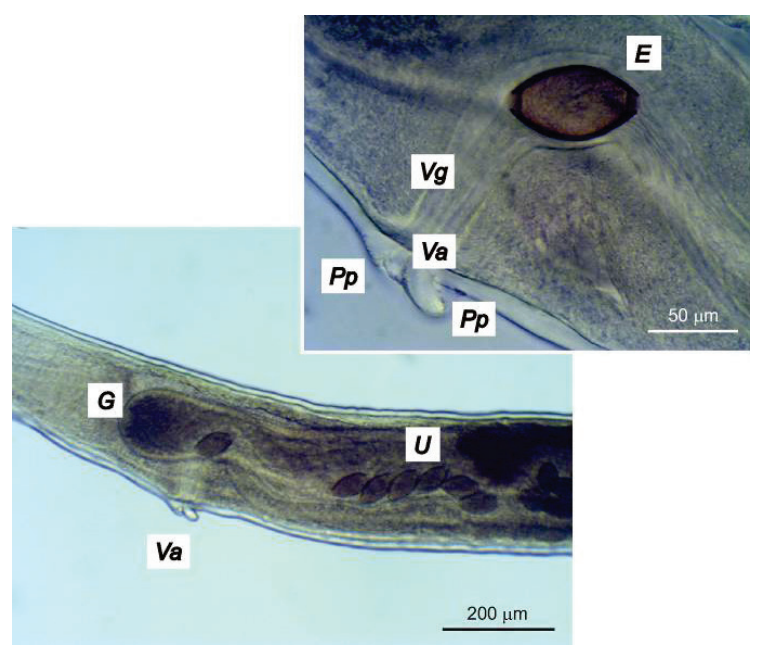

Fig. 5. + Trichuris vulpis: $V a-$ area of vulva, $V g-$ vagina, $U$-uterus, $P p$ - papillary processes, $E$ - egg, $G$ - gut
Papillary processes were characteristic near the vulval opening. The processes were of different sizes and shapes. The vagina was tubular, muscular, short and slightly bent (Fig. 5). The uterus had thin muscular walls, in mature females it was filled with several layers of eggs (Fig. 6a). The tail end was bluntly rounded. The anus was terminal (Fig. 6b).

Eggs obtained from uteri of the mature T. vulpis females insignificantly varied from barrel-shaped to lemon-shaped. Both symmetrical and somewhat oblate on one side eggs were observed. There were plugshaped protrusions on both egg ends. Egg shell was smooth and quite thick. Notably, the external shell layer covered egg plugs. Egg colour varied from dark yellow to dark brown (Fig. 7). T. vulpis males and females were measured, resulting in the following characters, useful for species identification. Also in the nematodes of this species, sexual dimorphism was easily observed (Table 1).

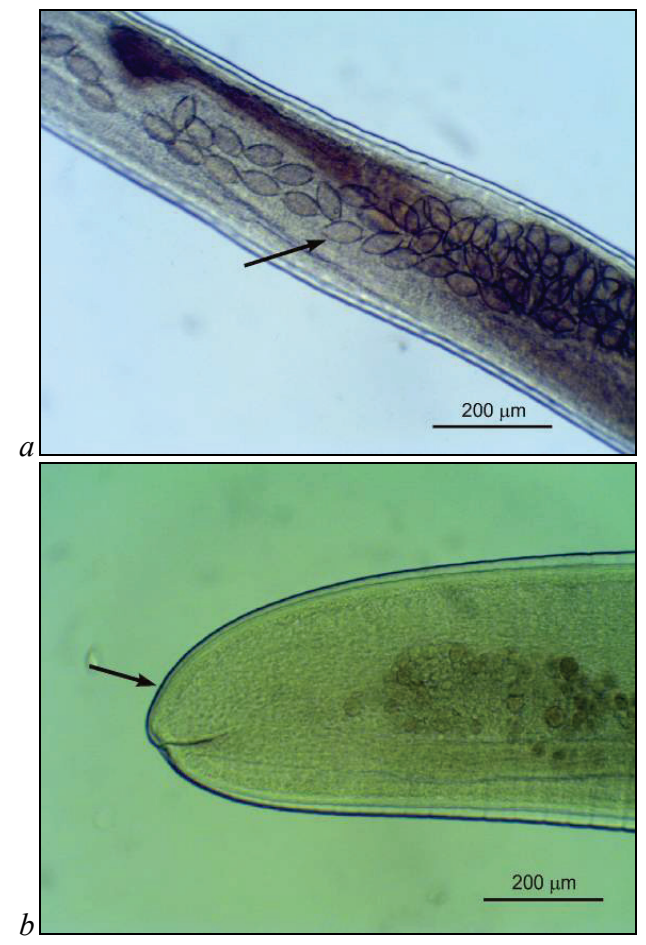

Fig. 6. + Trichuris vulpis: $a$ - uterus filled with eggs, $b$ - tail end

Thus, the male and female $T$. vulpis nematodes were statistically different by nine metric parameters. By seven of them, female nematodes were larger than males. However by two characters male nematodes were significantly larger than females. It was established that females were longer by $12.7 \%(\mathrm{P}<0.001)$ than males. Particularly, the female head end was longer by $21.3 \%(\mathrm{P}<0.001)$. The body area with 
cuticular processes was longer in females by $11.0 \%(\mathrm{P}<0.01)$ compared to males. The female nematode bodies were wider at: anterior edge of cuticular processes (by $7.9 \%, \mathrm{P}<0.001$ ); transition of esophagus to gut (by $8.5 \%, \mathrm{P}<0.001$ ); tail end (by $23.3 \%, \mathrm{P}<0.001$ ). The length ratio of head to tail body parts was $2.5: 1$ in females and $1.8: 1$ in males. At the same time the distance between head end and cuticular processes and the width of body at the middle of head body part were larger in males $(\mathrm{P}<0.001)$ by $19.1 \%$ and $11.5 \%$ compared to the respective values for females.

In males, 10 additional metric parameters were recommended for species identification (Table 2). It is most important to consider the spicule measurements, namely its length $(8.6 \pm 0.4 \mathrm{~mm})$ and width, which gradually increased from minimum at the distal part $(13.8 \pm 1.1 \mu \mathrm{m})$ to the middle $(22.3 \pm 1.0 \mu \mathrm{m})$ and maximum at its proximal part $(52.2 \pm$ $2.2 \mu \mathrm{m})$. Also, the metric parameters of the spicule sheath width consistently repeated at various spicule sheath parts. The proximal part of the spicule sheath was the widest $(128.8 \pm 7.0 \mu \mathrm{m})$, gradually tapering to the anus area (to $40.1 \pm 1.7 \mu \mathrm{m}$ ), after which the spicule sheath slightly widened at the distal end $(47.2 \pm 1.8 \mu \mathrm{m})$. Surface spikes of the spicule sheath were $1.6 \pm 0.1 \mu \mathrm{m}$ long.

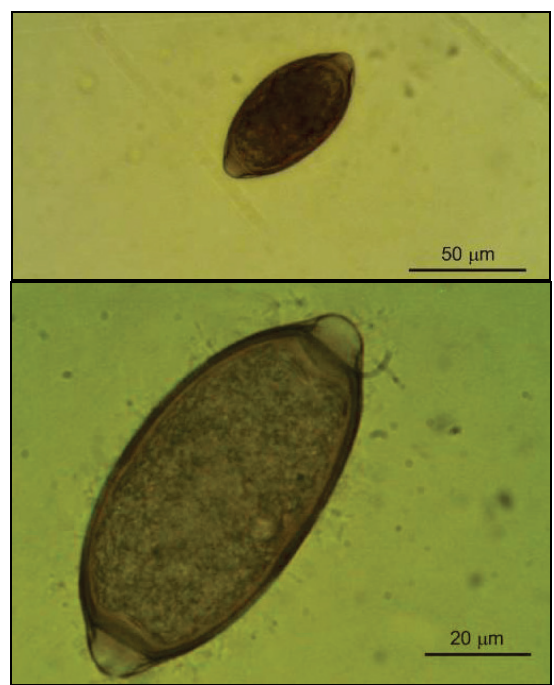

Fig. 7. Morphological structure of Trichuris vulpis egg

Table 1

Metric characters of sexual dimorphism in Trichuris vulpis $(\mathrm{x} \pm \mathrm{SD}, \mathrm{n}=10)$

\begin{tabular}{|c|c|c|c|c|}
\hline \multirow{2}{*}{ Characters } & \multicolumn{2}{|c|}{$\hat{0}$} & \multicolumn{2}{|c|}{9} \\
\hline & $\mathrm{x} \pm \mathrm{SD}$ & Min-Max & $\mathrm{x} \pm \mathrm{SD}$ & Min-Max \\
\hline Length of body, $\mathrm{mm}$ & $44.3 \pm 5.3$ & $37.0-52.1$ & $50.8 \pm 3.1^{* *}$ & $47.6-55.2$ \\
\hline Length of head part of body, mm & $28.6 \pm 4.5$ & $22.2-36.1$ & $36.4 \pm 2.4 * * *$ & $32.1-39.9$ \\
\hline Length of tail end of the body, $\mathrm{mm}$ & $15.6 \pm 2.1$ & $11.7-19.2$ & $14.4 \pm 1.2$ & $12.8-16.1$ \\
\hline Distance from head end to cuticular processes, $\mu \mathrm{m}$ & $732.9 \pm 26.1$ & $702.6-781.2$ & $592.6 \pm 24.6^{* * *}$ & $534.2-624.3$ \\
\hline Length of body part bearing cuticular processes, $\mu \mathrm{m}$ & $943.6 \pm 67.4$ & $826.8-1053.0$ & $1060.3 \pm 69.8^{* *}$ & $1001.8-198.5$ \\
\hline Width of body at: & & & & \\
\hline - anterior edge of cuticular processes, $\mu \mathrm{m}$ & $61.9 \pm 2.3$ & $59.1-65.6$ & $67.2 \pm 1.4 * * *$ & $65.2-69.5$ \\
\hline - posterior edge of cuticular processes, $\mu \mathrm{m}$ & $70.0 \pm 1.6$ & $67.8-72.6$ & $71.7 \pm 1.3$ & $70.0-74.6$ \\
\hline - middle part of head end of body, $\mu \mathrm{m}$ & $132.1 \pm 5.5$ & $122.8-145.1$ & $116.9 \pm 9.2^{* * *}$ & $108.5-132.8$ \\
\hline - transition of esophagus to gut, $\mu \mathrm{m}$ & $225.4 \pm 5.4$ & $216.8-234.1$ & $246.4 \pm 6.1 * * *$ & $238.0-254.2$ \\
\hline- tail end, $\mu \mathrm{m}$ & $393.0 \pm 17.4$ & $356.1-411.2$ & $512.6 \pm 19.4^{* * *}$ & $482.0-537.0$ \\
\hline Head to tail body part ratio & $1.8: 1$ & $1.2: 1-2.2: 1$ & $2.5: 1 * * *$ & $2: 1-2.8: 1$ \\
\hline
\end{tabular}

Note: $* *-\mathrm{P}<0.01,{ }^{* * *}-\mathrm{P}<0.001-$ compared to character values of $\hat{o}$.

Table 2

Metric parameters of $\widehat{\partial}$ Trichuris vulpis $(\mathrm{x} \pm \mathrm{SD}, \mathrm{n}=10)$

\begin{tabular}{lcc}
\hline \multicolumn{1}{c}{ Parameters } & $\mathrm{X} \pm \mathrm{SD}$ & \multicolumn{1}{c}{ Min-Max } \\
\hline Width of body at the proximal end of spicule, $\mu \mathrm{m}$ & $338.4 \pm 11.0$ & $322.8-351.5$ \\
Length of spicule, $\mathrm{mm}$ & $8.6 \pm 0.4$ & $7.9-9.2$ \\
Width of the proximal end of spicule, $\mu \mathrm{m}$ & $52.2 \pm 2.2$ & $47.8-55.0$ \\
Width of spicule in the middle, $\mu \mathrm{m}$ & $22.3 \pm 1.0$ & $20.1-24.3$ \\
Width of the distal end of spicule, $\mu \mathrm{m}$ & $13.8 \pm 1.1$ & $12.1-15.6$ \\
Width of spicule sheath at the proximal part, $\mu \mathrm{m}$ & $128.8 \pm 7.0$ & $118.6-137.1$ \\
Width of spicule sheath at the middle part, $\mu \mathrm{m}$ & $107.4 \pm 8.9$ & $90.5-118.2$ \\
Width of spicule sheath at anus, $\mu \mathrm{m}$ & $40.1 \pm 1.7$ & $36.0-42.1$ \\
Width of spicule sheath at the distal part, $\mu \mathrm{m}$ & $47.2 \pm 1.8$ & $44.6-50.0$ \\
Length of spikes at the spicule sheath, $\mu \mathrm{m}$ & $1.6 \pm 0.1$ & $1.3-1.7$ \\
\hline
\end{tabular}

Table 3

Metric parameters 9 Trichuris vulpis $(\mathrm{x} \pm \mathrm{SD}, \mathrm{n}=10)$

\begin{tabular}{lcc}
\hline \multicolumn{1}{c}{ Characters } & $\mathrm{x} \pm \mathrm{SD}$ & Min-Max \\
\hline Width of body at the vulva area, $\mu \mathrm{m}$ & $221.9 \pm 10.3$ & $207.6-241.9$ \\
$\begin{array}{l}\text { Distance from vulva to the head end, } \mathrm{mm} \\
\text { Distance from vulva to the transition }\end{array}$ & $51.0 \pm 3.1$ & $47.8-55.4$ \\
of esophagus to gut, $\mu \mathrm{m}$ & $162.7 \pm 11.3$ & $140.6-178.7$ \\
Distance from vulva to anus, $\mathrm{mm}$ & $14.2 \pm 1.1$ & $12.7-15.9$ \\
Width of the area with papillary processes & $64.2 \pm 2.9$ & $59.8-68.1$ \\
at the vulva area, $\mu \mathrm{m}$ & $14.4 \pm 1.1$ & $12.1-15.6$ \\
Height of the proximal papillary process, $\mu \mathrm{m}$ & $17.5 \pm 0.9$ & $16.0-19.1$ \\
Width of the proximal papillary process, $\mu \mathrm{m}$ & $19.9 \pm 0.9$ & $18.4-21.0$ \\
Height of the distal papillary process, $\mu \mathrm{m}$ & $28.6 \pm 1.3$ & $25.4-30.1$ \\
Width of the distal papillary process, $\mu \mathrm{m}$ & &
\end{tabular}

In female nematodes, nine metric parameters were recommended for species identification (Table 3). The most important of the aforementioned parameters were linked to the location of the vulva. The dis- tance from the vulva to the head end was $51.0 \pm 3.1 \mathrm{~mm}$, from the vulva to the transition of the esophagus to the gut $162.7 \pm 11.3 \mu \mathrm{m}$, and from the vulva to the anus $14.2 \pm 1.1 \mathrm{~mm}$. The papillary processes near the vulva should also be measured and taken into account. The distal papillary process was large $(19.9 \pm 0.9 \times 28.6 \pm 1.3 \mu \mathrm{m})$ compared to the proximal papillary process $(14.4 \pm 1.1 \times 17.5 \pm 0.9 \mu \mathrm{m})$.

The embryogenesis of $T$. vulpis in laboratory culture at $27{ }^{\circ} \mathrm{C} \mathrm{oc}-$ curred in five stages: protoplast, blastomere cleavage, and formation of bean-like embryo, larva and mobile larva. Each stage was morphologically distinct. Eggs developed to the infectious stage in 18 days, which is fast, and their survivability reached $76.6 \%$ (Table 4).

Table 4

Parameters of embryonic development in eggs obtained from gonads of Trichuris vulpis females, in laboratory culture $(\mathrm{x} \pm \mathrm{SD}, \mathrm{n}=100)$

\begin{tabular}{ccccccc}
\hline & \multicolumn{6}{c}{ Stage of development, \% } \\
\cline { 3 - 6 } $\begin{array}{c}\text { Day of } \\
\text { culture }\end{array}$ & protoplast & $\begin{array}{c}\text { blastomere } \\
\text { cleavage }\end{array}$ & $\begin{array}{c}\text { formation of } \\
\text { bean-like } \\
\text { embryo }\end{array}$ & larva & $\begin{array}{c}\text { mobile } \\
\text { larva }\end{array}$ & egg death \\
\hline 1 & 100.0 & - & - & - & - & - \\
3 & $65.0 \pm 4.0$ & $35.0 \pm 4.0$ & - & - & - & - \\
6 & $26.3 \pm 1.5$ & $52.6 \pm 2.1$ & $21.0 \pm 3.6$ & - & - & - \\
9 & - & $20.6 \pm 1.5$ & $32.3 \pm 2.5$ & $23.6 \pm 4.1$ & - & $23.3 \pm 2.1$ \\
12 & - & - & $13.0 \pm 2.0$ & $51.0 \pm 4.5$ & $12.6 \pm 1.5$ & $23.3 \pm 2.1$ \\
15 & - & - & - & $5.6 \pm 2.1$ & $71.0 \pm 1.0$ & $23.3 \pm 2.1$ \\
18 & - & - & - & - & $76.6 \pm 2.1$ & $23.3 \pm 2.1$ \\
\hline
\end{tabular}

All eggs obtained from female nematode gonads $(100 \%)$ were at the protoplast stage. At the third day of culture, $35.0 \%$ of eggs were at the blastomere cleavage stage. At the sixth day of culture, maximum eggs at the blastomere cleavage stage were observed, $52.6 \%$. At the same time, the morphological changes characteristic of bean-like embryo were 
noted in $21.0 \%$ of eggs. From the ninth day of culture, no eggs with protoplasts were seen, $20.6 \%$ of eggs remained at the blastomere cleavage stage and most of the rest $(32.3 \%)$ were at the bean-like embryo stage. The larva formation was recorded from ninth to 12th day of culture (from 23.6 to $51.0 \%$ of all eggs). Later, at the 12th day of culture, $12.6 \%$ of eggs contained a mobile larva, at the 15 th day $71.0 \%$ of eggs contained one, and on the 18 th day, $76.6 \%$. Overall, $23.3 \%$ of eggs did not develop and died in culture.

In morphometric study, it was established that measurements of T. vulpis eggs changed throughout their development in culture. Hence, the length and width of eggs obtained from the female nematode gonads at the protoplast stage were $86.4 \pm 2.5$ and $35.3 \pm 0.7 \mu \mathrm{m}$, respectively. The length and width of the egg plug were $6.1 \pm 0.5$ and $10.0 \pm$ $0.6 \mu \mathrm{m}$, and egg shell thickness was $1.5 \pm 0.1 \mu \mathrm{m}$. The infectious eggs with mobile larvae were shorter by $11.7 \%(76.3 \pm 2.3 \mu \mathrm{m})$ (Fig. $8 a)$, and their egg shell was thinner by $14.5 \%(1.3 \pm 0.1 \mu \mathrm{m})$ (Fig. $8 e$ ) compared to the initial values $(\mathrm{P}<0.001)$. Simultaneously, eggs widened by $18.9 \%$ $(43.6 \pm 2.6 \mu \mathrm{m})$ (Fig. $8 b)$. Egg plug width in matured eggs increased by $11.4 \%(11.2 \pm 0.6 \mu \mathrm{m})$ compared to protoplast egg values (Fig. $8 d$ ). The egg plug length $(6.5 \pm 0.4 \mu \mathrm{m})$ did not significantly change in culture (Fig. 8c). Those specifics in the metric parameters and morphological characteristics, and the periods of development of $T$. vulpis eggs should be considered in species identification.

\section{Discussion}

According to the scientific reports, Trichuris vulpis (Frölich, 1789) is a specific parasite of carnivore animals. However, it is also a zoonotic pathogen of certain danger to human health (Hall \& Sonnenberg, 1956; Singh et al., 1993; Mohd-Shaharuddin et al., 2019). This species is also common in the domestic dog (Canis lupus familiaris) in most of the world (Ramos et al., 2015; Scaramozzino et al., 2018; Opazo et al., 2019). Thus, human infection with T. vulpis is a matter of considerable importance since dogs are not only domestic pets but helpers of humans (Kenney \& Eveland, 1978; Kenney \& Yermakov, 1980; Dunn et al., 2002). Hence, further investigations of morphobiological specifics are needed concerning the nematodes of this species.

The morphometric study of adult females and males of $T$. vulpis established the metrics of sexual dimorphism in the nematodes of this species. Significant differences were found by nine metric parameters. By seven of those, females are larger than males: length of body (by 12.7\%, P < 0.001); length of head body part (by 21.3\%, P < 0.001 ); length of body area with the cuticular processes (by $11.0 \%, \mathrm{P}<0.01$ ); width of body at the higher edge of cuticular processes (by 7.9\%); width of body at the transition of esophagus to gut (by $8.5 \%$ ); width of body at the tail body part (by 23.3\%); head to tail length ratio (by $26.7 \%$ ). Conversely, males are larger by two parameters: distance from head end to the cuticular processes (by 19.1\%); width of body at the middle of the head end (by $11.5 \%$ ). The size dimorphism is reportedly one of the most common manifestations of sexual dimorphism, and understanding the reasons for the latter is one of the important questions of the evolutionary biology. For example, the fact that females of parasitic helminths are significantly larger than males is explained by the sexual selection of females by fertility (Morand, 1996; Poulin, 1997).

It is well-known that the species identification of helminths necessitates studying their morphological specifics and metric parameters. There is a history of reports on identification of $T$. vulpis by morphological characters (Skriabyn et al., 1957; Taylor et al., 2007). We have analyzed the morphobiological specifics of nematodes of this species, and determined the characteristic morphological specifics of $T$. vulpis males and females. We also suggest additional morphometric parameters to identify the species. One of the characters is the vesicular cuticular processes at the head end of the nematode. They occupy $1060.3 \pm 69.8 \mu \mathrm{m}$ of body length in females and $943.6 \pm 67.4 \mu \mathrm{m}$ in males. The cuticular processes have been considered in species identification of the genus also for T. serrata, obtained from the domestic cat (Ketzis, 2015).

The spikes in the proximal part of spicule sheath but not in its distal part are characteristic of the $T$. vulpis males. That character is easily seen at maximum protrusion of the spicule sheath as reported previously
(Skriabyn et al., 1957). Spicule size should also be considered. Its length is $8.6 \pm 0.4 \mathrm{~mm}$, its width depending on the measured area ranges 13.8 $\pm 1.1 \mu \mathrm{m}$ (distal end) to $52.2 \pm 2.2 \mu \mathrm{m}$ (proximal end). Spicule sheath width is not constant: at the proximal part it is $128.8 \pm 7.0 \mu \mathrm{m}$, near the anus it is $40.1 \pm 1.7 \mu \mathrm{m}$, at the distal part it is $47.2 \pm 1.8 \mu \mathrm{m}$. The males of $T$. vulpis can also be identified by the length of spikes on the spicule sheath. The females of $T$. vulpis are morphologically distinguished by two papillary processes near the vulval opening. Their metric parameters should also be considered, with the distal papillary process longer by $27.3 \%$ and wider by $38.7 \%$ compared to the proximal process. Parameters characterizing the location of the vulva are also important (distance to head end; to transition of esophagus to gut; to anus). Those additional parameters help to identify that species not only by males but by females too.

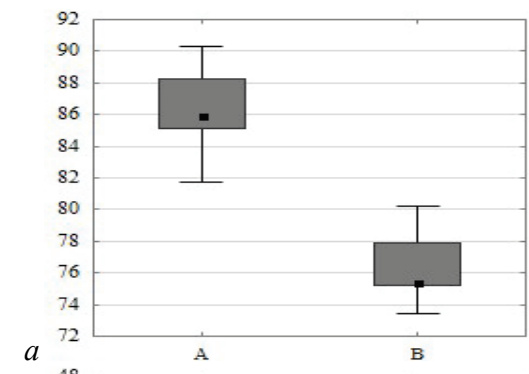

$a$

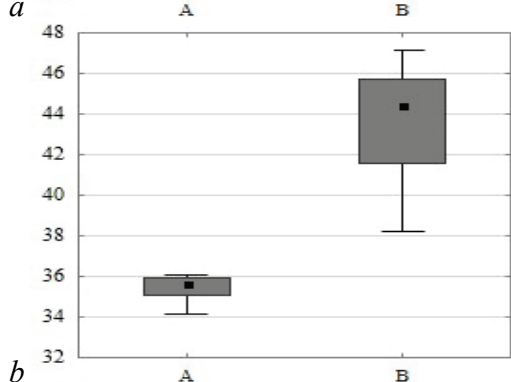

$b$
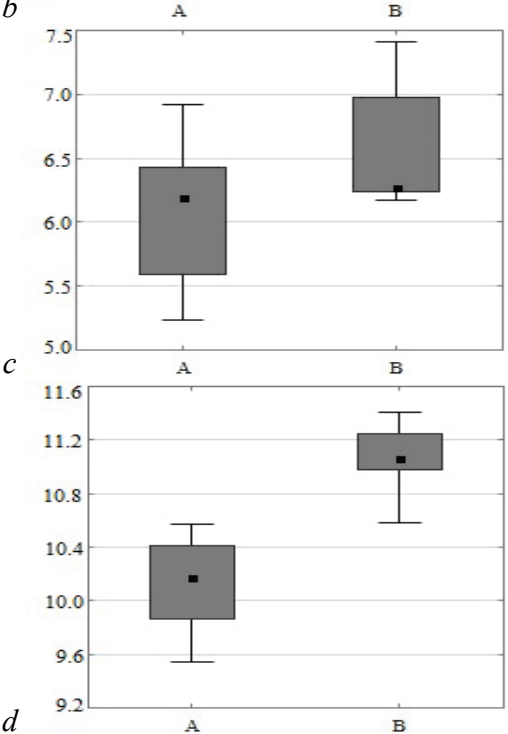

d

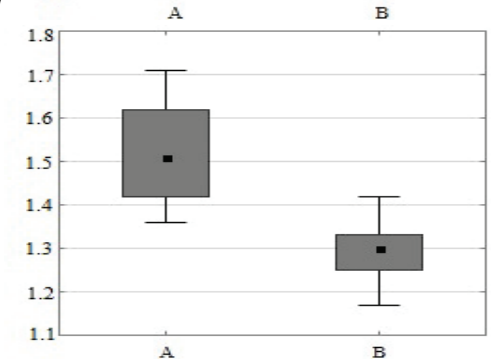

Fig. 8. Metric parameters of Trichuris vulpis eggs during embryogenesis $(\mu \mathrm{m})$ : $a$-length, $b$ - width, $c$ - egg plug length, $d$-egg plug width, $e$ - eggshell thickness; $A$ - protoplast stage, $B$ - mobile larva stage; $\mathrm{n}=10$ 
Many researchers point out the necessity of species identification of Trichuris at the egg stages because helminthological dissection and obtaining mature nematodes are not always possible. In that case, coprological analysis is the only method of diagnostics. Eggs of nematodes of the genus Trichuris in different species are similar by many morphological characters and are not easily identified by those. It is even more problematic in the case of differentiating between $T$. trichiura and T. vulpis. Hence, metric parameters are used together with the morphological specifics (Vásquez et al., 1997; Conboy, 2009; Di Cesare et al., 2012). We have established that the measurements of $T$. vulpis eggs obtained from female nematode gonads depend on the stage of development of the egg. Hence, the egg length can range 76.3 to $86.4 \mu \mathrm{m}$, egg width 35.3 to $43.6 \mu \mathrm{m}$, egg plug length 10.0 to $11.2 \mu \mathrm{m}$, egg plug width 6.1 to $6.5 \mu \mathrm{m}$, egg shell thickness 1.5 to $1.3 \mu \mathrm{m}$. However, only two or three parameters were used previously in species identification: length $(72-105 \mu \mathrm{m})$ and width $(32-44 \mu \mathrm{m})$ of eggs and length of egg plugs (9.0-12.0 $\mu \mathrm{m})$ (Skriabyn et al., 1957; Dunn et al., 2002; Márquez-Navarro et al., 2012).

In the embryogenesis of $T$. vulpis, five stages were observed in laboratory culture at $27^{\circ} \mathrm{C}$ : protoplast, blastomere cleavage, and formation of bean-like embryo, larva and mobile larva. The eggs become infectious in 18 days, while their survivability in culture is $76.6 \pm 2.1 \%$. Maximum number of eggs with protoplasts was noted at the first day of culture $(100 \%)$, that of eggs with cleaving blastomeres was seen at the sixth day $(52.6 \pm 2.1 \%)$. Maximum number of eggs with bean-like embryos was recorded at the ninth day of culture (32.3 $\pm 2.5 \%)$, that of larva-containing eggs was established at the 12th day of culture (51.0 \pm $4.5 \%$ ), and maximum of infectious eggs with mobile larvae was seen at the 18th day (76.6 $\pm 2.1 \%)$. Biology of Trichuris nematodes is a popular object of study. However, the embryogenesis is studied in the following species: T. ovis, T. skrjabini, T. globulosa (Thapar \& Singh, 1954; Yevstafieva et al., 2018; Melnychuk \& Berezovsky, 2018), Trichuris suis (Yevstafieva et al., 2015). The stages and periods of development in those species are significantly different from our data for $T$. vulpis. Our results add to the body of knowledge on the morphobiological specifics of $T$. vulpis nematodes, enhancing the species identification.

\section{Conclusion}

Our study revealed a significant sexual dimorphism in T. vulpis obtained from domestic dog. Differences were found in nine metric parameters. According to seven of those, female nematodes are larger than males, and by two males are conversely larger. In Trichuris species identification, the following should be considered: presence, location and metric parameters of the cuticular processes on the body surface. The presence of spikes in the proximal part of spicule sheath, in contrast to the lack of spikes on the distal part at maximum protrusion should be noted for the identification of adult males. In females, the most reliable morphological character is presence of papillary processes in the area of vulva. Ten morphometric characters for males and nine for females are proposed as additional parameters for species identification.

It was determined that the process of $T$. vulpis embryogenesis in laboratory conditions occurs in five stages: protoplast (1-6th day), blastomere cleavage ( 3 rd to 9 th day), bean-like embryo (6-12th day), larva (9-15th day), and mobile larva (12-18th day). The eggs become infectious in 18 days, and their average survivability is $76.6 \%$. In identification of $T$. vulpis eggs in coprological studies of samples obtained from humans and animals, the metric parameters of eggs should be considered, taking into account the egg stage of development. During egg development, the following characters change: length (decreases from 86.4 to $76.3 \mu \mathrm{m}$ ), shell width (decreases from 1.5 to $1.3 \mu \mathrm{m}$ ), width (increases from 35.3 to $43.6 \mu \mathrm{m}$ ), plug width (increases from 10.0 to $11.2 \mu \mathrm{m}$ ) and plug length (increases from 6.1 to $6.5 \mu \mathrm{m}$ ).

\section{References}

Adriko, M., Tinkitina, B., Arinaitwe, M., Kabatereine, N. B., Nanyunja, M., \& Tukahebwa, E. M. (2018). Impact of a national deworming campaign on the prevalence of soil-transmitted helminthiasis in Uganda (2004 2016): Impli- cations for national control programs. PLOS Neglected Tropical Diseases, 12(7), e0006520

Anderson, R. C. (2000). Nematode parasites of vertebrates: Their development and transmission. CABI Publishing, Wallingford.

Areekul, P., Putaporntip, C., Pattanawong, U., Sitthicharoenchai, P., \& Jongwutiwes, S. (2010). Trichuris vulpis and T. trichiura infections among schoolchildren of a rural community in Northwestern Thailand: The possible role of dogs in disease transmission. Asian Biomedicine, 4, 49-60.

Barutzki, D., \& Schaper, R. (2003). Endoparasites in dogs and cats in Germany 1999-2002. Parasitology Research, 90(3), 148-150.

Bethony, J., Brooker, S., Albonico, M., Geiger, S. M., Loukas, A., Diemert, D., \& Hotez, P. J. (2006). Soil-transmitted helminth infections: Ascariasis, trichuriasis, and hookworm. Lancet, 367, 1521-1532.

Betson, M., Søe, M. J., \& Nejsum, P. (2015). Human trichuriasis: Whipworm genetics, phylogeny, transmission and future research directions. Current Tropical Medicine Reports, 2(4), 209-217.

Boyko, A. A., \& Brygadyrenko, V. V. (2016). Influence of water infusion of medicinal plants on larvae of Strongyloides papillosus (Nematoda, Strongyloididae). Visnyk of Dnipropetrovsk University. Biology, Ecology, 24(2), 519-525.

Boyko, A. A., \& Brygadyrenko, V. V. (2017). Changes in the viability of the eggs of Ascaris suum under the influence of flavourings and source materials approved for use in and on foods. Biosystems Diversity, 25(2), 162-166.

Callejón, R., Robles, M. D. R., Panei, C. J., \& Cutillas, C. (2016). Molecular diversification of Trichuris spp. from Sigmodontinae (Cricetidae) rodents from Argentina based on mitochondrial DNA sequences. Parasitology Research, $115,1-13$.

Conboy, G. A. (2009). Helminth parasites of the canine and feline respiratory tract. Veterinary Clinics of North America: Small Animal Practice, 39, 1109-1126.

Di Cesare, A., Castagna, G., Meloni, S., Otranto, D., \& Traversa, D. (2012). Mixed trichuroid infestation in a dog from Italy. Parasites and Vectors, 5, 128.

Dunn, J. J., Columbus, S. T., Aldeen, W. E., Davis, M., \& Carroll, K. C. (2002) Trichuris vulpis recovered from a patient with chronic diarrhea and five dogs. Journal of Clinical Microbiology, 40(7), 2703-2704.

Eo, K. Y., Seo, M. G., Lee, H. H., Jung, Y. M., Kwak, D., \& Kwon, O. D. (2019). Severe whipworm (Trichuris spp.) infection in the hamadryas baboon (Papio hamadryas). Journal of Veterinary Medical Science, 81(1), 53-56.

Fahmy, M. A. M. (1954). An investigation on the life cycle of Trichuris muris. Parasitology, 44(1-2), 50-57.

Fataliev, G. G. (2013). Influence of abiotic factors on the embryonal development of Trichocephalus myocastoris (Nematoda, Trichocephalidae). Zoological Journal, 92(12), 1475-1477.

Ghai, R. R., Simons, N. D., Chapman, C. A., Omeja, P. A., Davies, T. J., Ting, N., \& Goldberg, T. L. (2014). Hidden population structure and cross-species transmission of whipworms (Trichuris sp.) in humans and non-human primates in Uganda. PLoS Neglected Tropical Diseases, 8(10), e3256.

Hall, J. E., \& Sonnenberg, B. (1956). An apparent case of human infection with the whipworm of dogs, Trichuris vulpis (Froelich, 1789). Journal of Parasitology, 42, 197-199.

Hasegawa, H. \& Dewi, K. (2017). Two new species of Trichuris (Nematoda: Trichuridae) collected from endemic murines of Indonesia. Zootaxa, 4254(1), 127-135.

Kagei, N., Hayashi, S., \& Kato, K. (1986). Human cases of infection with canine whipworms, Trichuris vulpis (Froelich, 1789), in Japan. Japanese Journal of Medical Science and Biology, 39, 177-184.

Karamon, J., Dąbrowska, J., Kochanowski, M., Samorek-Pieróg, M., Sroka, J., Różycki, M., Bilska-Zając, E., Zdybel, J., \& Cencek, T. (2018). Prevalence of intestinal helminths of red foxes (Vulpes vulpes) in Central Europe (Poland): A significant zoonotic threat. Parasites and Vectors, 11, 436.

Kenney, M., \& Eveland, L. K. (1978). Infection of man with Trichuris vulpis, the whipworm of dogs. American Journal of Clinical Pathology, 69(2), 199.

Kenney, M., \& Yermakov, V. (1980). Infection of man with Trichuris vulpis, the whipworm of dogs. American Journal of Tropical Medicine and Hygiene, $29,1205-1208$

Ketzis, J. K. (2015). Trichuris spp. infecting domestic cats on St. Kitts: Identification based on size or vulvar structure? Springerplus, 4, 115 .

Lee, D. L. (2002). The biology of nematodes. Taylor and Francis, London.

Márquez-Navarro, A., García-Bracamontes, G., Alvarez-Fernández, B. E., ÁvilaCaballero, L. P., Santos-Aranda, I., Díaz-Chiguer, D. L., Sánchez-Manzano, R. M., Rodríguez-Bataz, E., \& Nogueda-Torres, B. (2012). Trichuris vulpis (Froelich, 1789) infection in a child: A case report. Korean Journal of Parasitology, 50(1), 69-71.

Melnychuk, V. V., \& Berezovsky, A. V. (2018). Comparative embryonic development of nematodes of the genus Trichuris (Nematoda, Trichuridae) obtained from sheep (Ovis aries). Biosystems Diversity, 26(4), 257-262.

Mohd-Shaharuddin, N., Lim, Y. A. L., Hassan, N. A., Nathan, S., \& Ngui, R. (2019) Molecular characterization of Trichuris species isolated from humans, dogs and cats in a rural community in Peninsular Malaysia. Acta Tropica, 190, 269-272. 
Morand, S. (1996). Life-history traits in parasitic nematodes: A comparative approach for the search of invariants. Functional Ecology, 10, 210-218.

Mukaratirwa, S., \& Singh, V. P. (2010). Prevalence of gastrointestinal parasites of stray dogs impounded by the Society for the Prevention of Cruelty to Animals (SPCA), Durban and Coast, South Africa. Journal of the South African Veterinary Association, 81(2), 123-125.

Opazo, A., Barrientos, C., Sanhueza, A. M., Urrutia, N., \& Fernández, I. (2019) Fauna parasitaria en caninos (Canis lupus familiaris) de un sector rural de la región central de Chile. Revista de Investigaciones Veterinarias del Perú, $30(1), 330-338$.

Poulin, R. (1997). Covariation of sexual size dimorphism and adult sex ratio in parasitic nematodes. Biological Journal of the Linnean Society, 62(4), 567-580.

Pullan, R. L., Smith, J. L., Jasrasaria, R., \& Brooker, S. J. (2014). Global numbers of infection and disease burden of soil transmitted helminth infections in 2010. Parasites and Vectors, 7, 37.

Ramos, D. G. de S., Zocco, B. K. A., Torres, M. de M., Hsis, A. B., Pacheco R. de C., \& Sinkoc, A. L. (2015). Helminths parasites of stray dogs (Canis lupus familiaris) from Cuiabá, Midwestern of Brazil. Semina Ciencias Agrarias, 36(2), 889-894.

Redman, W. K., Bryant, J. E., \& Ahmad, G. (2016). Gastrointestinal helminths of Coyotes (Canis latrans) from Southeast Nebraska and Shenandoah area of Iowa. Veterinary World, 9(9), 970-975.

Robles, M. R., Navone, G. T., \& Notarnicola, J. (2006). A new species of Trichuris (Nematoda: Trichuriidae) from Phyllotini rodents in Argentina. Journal of Parasitology, 92, 100-104.

Sakano, T., Hamamoto, K., Kobayashi, Y., Sakata, Y., Tsuji, M., \& Usui, T. (1980). Visceral larva migrans caused by Trichuris vulpis. Archives of Disease in Childhood, 55(8), 631-633.

Scaramozzino, P., Carvelli, A., Iacoponi, F., \& De Liberato, C. (2018). Endoparasites in household and shelter dogs from Central Italy. International Journal of Veterinary Science and Medicine, 6(1), 45-47.

Singh, S., Samantaray, J. C., Singh, H., Das, G. B., \& Verma, I. C. (1993). Trichuris vulpis infection in an Indian tribal population. Journal of Parasithology, 79(3), 457-458.

Skrjabin, K. I. (1928). Metod polnyh gel'mintologicheskih vskrytij pozvonochnyh, vkljuchaja cheloveka [The method of complete helminthological autopsy of vertebrates, including humans]. First Moscow State University, Moscow (in Russian).

Skrjabin, K. I., Shikhobalova, N. P., \& Orlov, I. V. (1957). Trihocefalidy i kapilljariidy zhivotnyh i cheloveka i vyzyvaemye imi zabolevanija [Trichocephalids and capillariids of animals and man and the diseases caused by them. The essentials of nematodology]. Academy of Sciences of the USSR, Moscow (in Russian).

Soulsby, E. J. L. (1982). Helminths, arthropods and protozoa of domesticated animals (7th edition). Bailliere Tindall, London.
Spakulová, M. (1994). Discriminant analysis as a method for the numerical evaluation of taxonomic characters in male trichurid nematodes. Systematic $\mathrm{Pa}-$ rasitology, 29, 113-119.

Stephenson, L. S., Holland, C. V., \& Cooper, E. S. (2000). The public health significance of Trichuris trichiura. Parasitology, 121(1), 73-95.

Stroehlein, A. J., Young, N. D., Korhonen, P. K., Chang, B. C. H., Nejsum, P., Pozio, E., La Rosa, G., Sternberg, P. W., \& Gasser, R. B. (2017). Whipworm kinomes reflect a unique biology and adaptation to the host animal. International Journal for Parasitology, 47(13), 857-866.

Taylor, M. A., Coop, R. L., \& Wall, R. L. (2007). Veterinary parasitology (3th edition). Blackwell Publishing, Oxford.

Thapar, G. S., \& Singh, K. S. (1954). Studies on the life-history of Trichuris ovis (Abildgaard, 1795) (fam. Trichuridae: Nematoda). Proceedings of the Indian Academy of Sciences, 40(3), 69-88.

Varodi, E. I., Malega, A. M., Kuzmin, Y. I., \& Kornyushin, V. V. (2017). Helminths of wild predatory mammals of Ukraine. Nematodes. Vestnik Zoologii, 51(3), $187-202$.

Vásquez, T. O., Martínez, B. I., Romero, C. R., Valencia, R. S., \& Tay, Z. J. (1997) Mixed infection by Trichuris trichiura and Trichuris vulpis. Revista de Gastroenterología del Perú, 17, 255-258.

Xie, Y., Zhao, B., Hoberg, E. P., Li, M., Zhou, X., Gu, X., Lai, W., Peng, X., \& Yang, G. (2018). Genetic characterisation and phylogenetic status of whipworms (Trichuris spp.) from captive non-human primates in China, determined by nuclear and mitochondrial sequencing. Parasites and Vectors, 11(1), 516

Yevstafieva, V. A., Yuskiv, I. D., Melnychuk, V. V., Yasnolob, I. O., Kovalenko, V. A., \& Horb, K. O. (2018). Nematodes of the genus Trichuris (Nematoda Trichuridae) parasitizing sheep in central and south-eastern regions of Ukraine. Vestnik Zoologii, 52(3), 553-556.

Yevstafieva, V. A., Melnichuk, V. V., Sharavara, T. A Sirenko, E. V., Makarevich, N. A., Kutsenko, Y. P., \& Khlevnaya, G. S. (2018). Osobennosti embrional'nogo razvitija jaic nematod Trichuris skrjabini (Baskakov, 1924), parazitirujushhih u ovec [Specific features of embryonic development of Trichuris skrjabini (Baskakov, 1924) nematode eggs parasitizing in sheep]. An Agrarian Science of Euro-North-East, 62(1), 65-69 (in Russian).

Yevstafieva, V. A., Yuskiv, I. D., \& Melnychuk, V. V. (2015). An investigation of embryo and eggshell development in Trichuris suis (Nematoda, Trichuridae) under laboratory conditions. Vestnik Zoologii, 50(2), 173-178.

Yoshikawa, H., Yamada, M., Matsumoto, Y., \& Yoshida, Y. (1989). Variations in egg size of Trichuris trichiura. Parasitology Research, 75, 649-654.

Zanzani, S. A., Gazzonis, A. L., Scarpa, P., Berrilli, F., \& Manfredi, M. T. (2014). Intestinal parasites of owned dogs and cats from metropolitan and micropolitan areas: Prevalence, zoonotic risks, and pet owner awareness in Northern Italy. BioMed Research International, 2014, 696508 